\title{
Subspecific differentiation of Burkholderia cepacia isolates in cystic fibrosis
}

\author{
M. A. LiVesley, I. A. BAXTER, P. A. LAMBERT, J. R. W. GOVAN*, P. H. WELLER†, \\ D. E. LACEY $¥$, D. G. ALLISON\&, B. GIWERCMAN\| and N. HOIBY\| \\ Microbiology Research Group, Department of Pharmaceutical and Biological Sciences, Aston University, \\ Birmingham, *Department of Medical Microbiology, University of Edinburgh, Edinburgh, †Birmingham \\ Children's Hospital, Birmingham, ¥Wirral Hospital, Upton, Wirral, §School of Pharmacy and Pharmaceutical \\ Sciences, University of Manchester, UK and \|Department of Clinical Microbiology, Rigshospitalet, Copenhagen \\ 2100, Denmark
}

\begin{abstract}
Thirty clinical isolates of Burkholderia cepacia from cystic fibrosis (CF) patients in the UK and Denmark were characterised, together with other clinical isolates and laboratory strains of $B$. cepacia, B. gladioli and $B$. vietnamiensis. Outer-membrane protein (OMP) profiles were determined, and the organisms were typed genotypically by pulsed-field gel electrophoresis after DNA restriction analyses with $X b a I$ and Dra I. This latter method revealed four clusters among the clinical isolates studied; one of these contained isolates of the UK and intercontinental CF epidemic lineage ET12, a cluster which appeared to contain three subtypes. Each of the four clusters appeared less closely related to laboratory strains of $B$. cepacia than were laboratory strains of $B$. vietnamiensis, but more closely related to both these species than to $B$. gladioli. Two types of OMP profile were distinguished among the clinical isolates and strains, and were designated $A$ and $B$. In type $A$ isolates the major proteins had mol.wts of 39, 27 and $18 \mathrm{kDa}$. Type $B$ strains additionally contained a group of proteins in the size range 80-90 kDa, although detection of these depended upon the conditions for sample denaturation. In most cases, the OMP type correlated with the genotype, suggesting that examination of OMPs might be of value in the initial characterisation of isolates.
\end{abstract}

\section{Introduction}

Infection with Burkholderia cepacia is a recognised complication in the progression of pulmonary disease in cystic fibrosis (CF) patients $[1,2]$. The organism is also a pathogen in individuals immunocompromised by chronic granulomatous disease (CGD) and AIDS $[3,4]$. B. cepacia shows considerable metabolic diversity, but is less prevalent in the environment than was once thought [5-7]. It has innate resistance to many antibiotics and treatment is difficult $[8,9]$. The prognosis for $B$. cepacia-positive CF patients is variable, ranging from asymptomatic carriage to a fatal necrotising pneumonia with septicaemic complications [10]. This latter progression is sometimes called 'B. cepacia syndrome' $[11,12]$.

Received 19 Dec. 1997; revised version received 24 Feb. 1998; accepted 26 Feb. 1998.

Corresponding author: Dr M. A. Livesley.
Compelling evidence for person-to-person transmission of $B$. cepacia in $\mathrm{CF}$ patients has been established by molecular typing $[13,14]$ and the prevalence of certain highly transmissible strains has been described [15]. These include an epidemic strain, ET12, responsible for many $B$. cepacia infections in the UK and North America $[15,16]$. This strain is highly transmissible, with even brief close contact appearing to permit passage between $\mathrm{CF}$ patients $[15,17,18]$. Segregative policies have reduced the incidence of $B$. cepacia in CF patients $[16,17]$, but reports describing the delayed detection of this organism highlight the importance of continued vigilance [1]. Distinguishing those strains that do and do not readily cause crossinfection has the potential to benefit $B$. cepaciapositive CF patients.

However, the role of epidemic strains is not universal. Polymerase chain reaction, ribotyping and pulsed-field gel electrophoresis (PFGE) identified eight distinct $B$. cepacia genotypes among isolates from the Danish CF population [19] and, in contrast to the UK and North 
America, there was no evidence for nosocomial crossinfection, even though most $\mathrm{CF}$ patients regularly attend the same CF clinic [19].

Genomic analysis by PFGE is a powerful method for distinguishing strains in many species including $B$. cepacia $[14,20]$ but is expensive and demanding, and a simpler phenotypic characterisation might be useful in distinguishing between strains before a more detailed analysis is carried out. Analysis of outermembrane protein (OMP) profiles by SDS-PAGE allows rapid, phenotypic characterisation and has been applied successfully to, e.g., Haemophilus influenzae [20]. In B. cepacia, the OMP profile is characterised either by a major protein with an apparent mol.wt of $39 \mathrm{kDa}$ or a cluster of proteins in the $80-90-\mathrm{kDa}$ size range [21]. Detailed analysis has shown that the high mol.wt cluster is a complex of subunits of 39 and $27 \mathrm{kDa}$, which resists denaturation by heat before electrophoretic analysis [22].

This study examined $\mathrm{CF}$ isolates of $B$. cepacia obtained from two sources (the UK and Denmark) by PFGE and OMP profiling and found that OMP profiles may provide a rapid means of making an initial distinction among isolates.

\section{Materials and methods}

\section{Strains}

Clinical isolates and laboratory strains of $B$. cepacia, B. gladioli and B. vietnamiensis were obtained from the sources indicated in Table 1. Each strain was stored in nutrient broth supplemented with glycerol $10 \% \mathrm{v} / \mathrm{v}$ at $-70^{\circ} \mathrm{C}$ until use. Pseudomonas aeruginosa NCTC 6750, P. aeruginosa ATCC 15692 and Stenotrophomonas maltophilia NCTC 10257 were included as controls. All strains were maintained on MuellerHinton Agar (Oxoid).

\section{Preparation of high-mol.-wt genomic DNA}

Fifty $\mathrm{ml}$ of Mueller-Hinton Broth were inoculated with a single colony from a $36-\mathrm{h}$ culture grown at $37^{\circ} \mathrm{C}$ on Mueller-Hinton Agar. The liquid culture was then incubated for $48 \mathrm{~h}$ at $37^{\circ} \mathrm{C}$ with continuous shaking, before harvesting by centrifugation at $10000 \mathrm{~g}$ for $10 \mathrm{~min}$ at $25^{\circ} \mathrm{C}$. The cells were washed twice in sterile $\mathrm{NaCl} 0.9 \%$ solution and then resuspended in $1 \mathrm{ml}$ of NET-100 $(0.1 \mathrm{M} \mathrm{NaCl}, 0.1 \mathrm{M}$ EDTA, pH 8.0, $0.1 \mathrm{M}$ Tris- $\mathrm{HCl}, \mathrm{pH} 8.0$ ) at a density of $5 \mathrm{mg} / \mathrm{ml}$ (wet weight). This suspension was used to prepare agarose plugs for PFGE according to the method of Rainey et al. [23].

\section{Restriction digestion of DNA and PFGE}

Two restriction endonucleases were used: $X b a$ I (which recognises the sequence 5'-TCTAGA) and DraI (5'TTTAAA). Portions $(1 \times 1 \times 9 \mathrm{~mm})$ of agarose plugs containing high mol.wt DNA were digested by the method of Rainey et al. [23] and samples were subjected to PFGE on a BioRad CHEF DRIII apparatus (CA, USA) with $0.5 \times \mathrm{TBE}(1 \times \mathrm{TBE}$ is $90 \mathrm{mM}$ Trisborate and $1 \mathrm{mM}$ EDTA, $\mathrm{pH} 8.0$ ) buffer in agarose (BioRad) $1.2 \%$. The ramped pulse time was $7-60 \mathrm{~s}$ (Xba I digests) or $2-25 \mathrm{~s}$ (Dra I) for $22 \mathrm{~h}$ at $6 \mathrm{~V} / \mathrm{cm}$ with a $120^{\circ}$ electrode angle. The gels were stained with ethidium bromide $0.5 \mathrm{mg} / \mathrm{L}$ for $30 \mathrm{~min}$, de-stained in distilled water, and examined by means of a scanner (UVP Products, Cambridge). At least two independent separations of the restriction fragments were performed to confirm reproducibility.

\section{Evaluation of pulsed-field gels}

Band sizes were estimated with the Gelworks 1D software package (UVP Products) and the numerical method of Grothues and Tümmler [24] was used to assess statistically the relatedness of the strains. A computer-based spreadsheet (Microsoft Excel) was

Table 1. Origin of strains and isolates used in this study

\begin{tabular}{|c|c|}
\hline Strain identifier & Source \\
\hline $\begin{array}{l}\text { 5BI; 5JIV; 5NVI; 5PII; 5PIV; 5PVI; 5QIV; 5QV; 5RIV; 5SI. } \\
\text { 5QIV. } \\
\text { 5OV; 5PI. } \\
\text { 5RI; 5RII; 5RIII. } \\
\text { C1948; J2315 (both epidemic ET12 isolates) } \\
\text { J2552. } \\
\text { 5SV; 5SVI; 5TI; 5TII; 5TIII; 5TIV; 5TV. } \\
\text { 3843; 3925; 4325; } 4326 ; 4949 ; 9275 ; 12794 ; 15836 . \\
\text { B. cepacia ATCC } 17616 \\
\text { B. cepacia NCTC } 10744 \\
\text { B. cepacia NCTC } 10661 \\
\text { B. gladioli ATCC } 10248 \\
\text { B. gladioli ATCC } 10854 \\
\text { B. gladioli ATCC } 25417 \\
\text { B. vietnamiensis LMG } 6998 \\
\text { S. maltophilia NCTC } 10257 \\
\text { P. aeruginosa NCTC } 6750 \\
\text { P. aeruginosa ATCC } 15692\end{array}$ & $\begin{array}{l}\text { CF, Birmingham } \\
\text { Burn isolate, Birmingham } \\
\text { Chronic granulomatous disease isolates, Birmingham } \\
\text { CF, Manchester } \\
\text { CF, Edinburgh [15] } \\
\text { Botanical isolate, Edinburgh [7] } \\
\text { CF, Liverpool } \\
\text { CF, Copenhagen } \\
\text { Soil } \\
\text { Blood culture } \\
\text { Trinidad, forest soil } \\
\text { Gladiolus leaf } \\
\text { Onion } \\
\text { Gladiolus leaf } \\
\text { Blood culture } \\
\text { Buccal cavity } \\
\text { Urine } \\
\text { Wound infection }\end{array}$ \\
\hline
\end{tabular}

ATCC, American Type Culture Collection; NCTC, National Collection of Type Cultures (UK); LMG, University of Ghent Culture Collection, Belgium. 
used to assist in this process. Relatedness was determined by comprehensive pair-wise comparison of restriction fragment sizes within the sample group. This permitted the calculation of the Dice coefficient $\left(S_{D}\right)$ for each pair. The gel photographs were divided into suitable intervals; Xba I-digested samples and Dra I-digested samples were deemed to possess 28 and 40 intervals, respectively. Statistical significance was then evaluated by the equation described by Grothues and Tümmler [24], and the hierarchical UPGMA method of analysis was used to group the strains into clusters based on the $S_{D}$ values. The computer-based statistical analysis software Unistat (Version 4.0) was used for this step and to generate a dendrogram of the data, working in unison with Microsoft Excel.

\section{OMPs}

Mueller-Hinton broth cultures (1 L) were inoculated with $50-\mathrm{ml}$ amounts of overnight broth cultures and incubated for $16 \mathrm{~h}$ with continuous shaking at $37^{\circ} \mathrm{C}$. The cells were then harvested by centrifugation at $10000 \mathrm{~g}$ for $10 \mathrm{~min}$ at $25^{\circ} \mathrm{C}$, washed once in water, then resuspended in $20 \mathrm{ml}$ of water containing deoxyribonuclease II $250 \mathrm{mg} / \mathrm{L}$ to reduce the viscosity on sonication. The cells were then ruptured by sonication (MSE Soniprep 150, MSE, Crawley, W. Sussex) with a logarithmic probe of tip diameter $4 \mathrm{~mm}$, operating at maximum power for 30 cycles of $30 \mathrm{~s}$ sonication, with intervening pauses of $30 \mathrm{~s}$ for cooling on ice. Any remaining whole cells were removed by centrifugation at $10000 \mathrm{~g}$, and the supernate was adjusted to $35 \mathrm{ml}$ with water. N-Lauroyl sarcosine was added to $2 \% \mathrm{w} / \mathrm{v}$, and the mixture was allowed to stand for $5 \mathrm{~min}$ to solubilise the cytoplasmic membranes. Centrifugation at $35000 \mathrm{~g}$ for $1 \mathrm{~h}$ at $4^{\circ} \mathrm{C}$ was then used to deposit a pellet containing partially purified outer membranes. This was resuspended in $35 \mathrm{ml}$ of N-lauroyl sarcosine $2 \% \mathrm{w} / \mathrm{v}$, left to stand for $5 \mathrm{~min}$ and re-centrifuged to yield a pellet containing purified outer membranes. These were resuspended in $2 \mathrm{ml}$ of water and stored at $-20^{\circ} \mathrm{C}$ for analysis by SDSPAGE.

\section{SDS-PAGE of OMPS}

Electrophoresis was performed in acrylamide $12 \% \mathrm{w} / \mathrm{v}$ gels prepared as described by Lugtenberg et al. [25]. Samples were denatured for $30 \mathrm{~min}$ at $100^{\circ} \mathrm{C}$ and subjected to SDS-PAGE on a Mini-Protean apparatus (BioRad). The gels subsequently were stained with Coomassie Blue.

\section{Results}

\section{OMP profiles}

Fig. 1a shows the OMP profiles determined by SDSPAGE for several isolates. The profiles of B. cepacia,

\section{a}

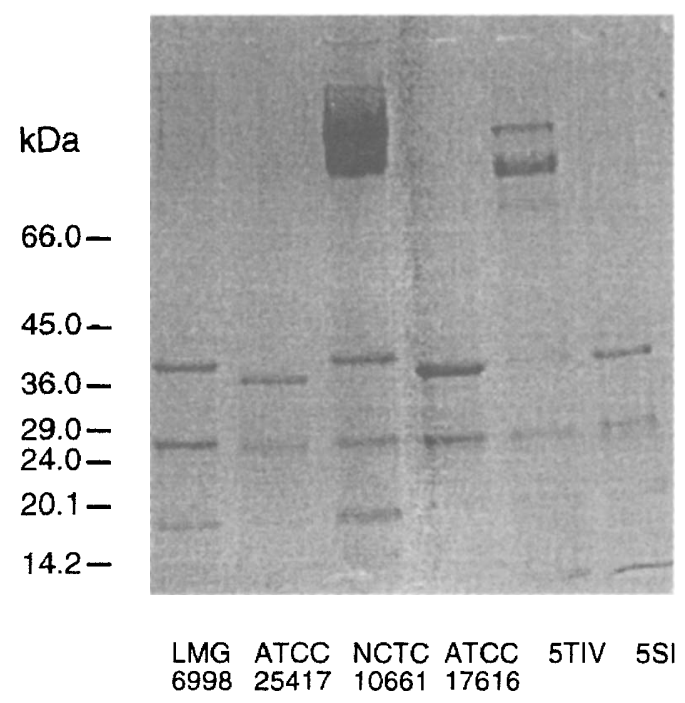

b

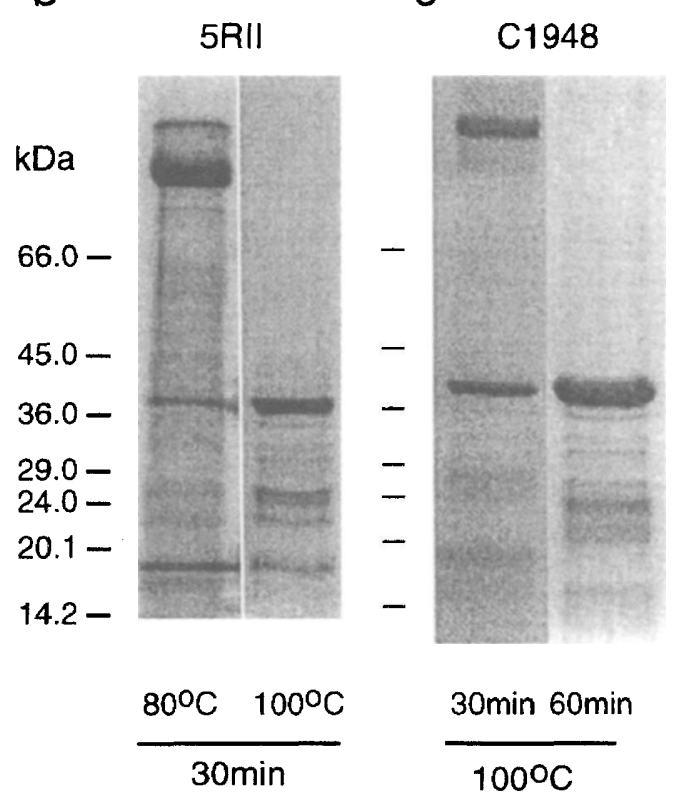

Fig. 1. (a) OMP profiles after denaturation at $100^{\circ} \mathrm{C}$ for $30 \mathrm{~min}$. The effects of other denaturing conditions are shown in (b) and (c) for two strains. Mol. wts are shown for standard protein markers.

B. gladioli and B. vietnamiensis each contained three major proteins in the range $14-39 \mathrm{kDa}$. In B. cepacia, two different protein profiles were observed when the outer membranes were denatured at $100^{\circ} \mathrm{C}$ for $30 \mathrm{~min}$. The first, termed type A, contained two major proteins, with mol. wt of 39 and $27 \mathrm{kDa}$, and a minor component around $18 \mathrm{kDa}$. The second profile, termed type $\mathrm{B}$, contained an additional complex of high mol.wt components in the region $80-90 \mathrm{kDa}$ as well as the 39-, 27- and (minor) 18-kDa bands. All the clinical isolates gave OMP patterns that could be grouped as type A or type B: the UK isolates comprised 11 of type $A$ and 15 type $B$, whereas the Danish isolates belonged exclusively to type A. The distinctive appearance of the type A and B OMP profiles was obtained only after 
denaturation for $30 \mathrm{~min}$ at $100^{\circ} \mathrm{C}$. When less rigorous heating $\left(80^{\circ} \mathrm{C}\right.$ for $\left.30 \mathrm{~min}\right)$ was used to denature the samples, all of the organisms produced type $\mathrm{B}$ profiles (Fig. 1b); whereas, after prolonged denaturation $\left(100^{\circ} \mathrm{C}\right.$ for $60 \mathrm{~min}$ ) all profiles converted to type A (Fig. 1c).

\section{Restriction digestion of the Burkholderia genome}

Two rarely cutting restriction endonucleases, $X b a \mathrm{I}$ and Dra I, were used to cleave the B. cepacia genome (Fig. 2), and yielded 28-30 bands. Other restriction endonucleases yielded too many or too few fragments for use in pairwise comparisons. Table 2 lists the $S_{D}$ calculated for representative strains, and a dendrogram showing the relatedness of the organisms is presented in Fig. 3. A single cluster is present above a distance of c. 0.58 Euclids, with subsequent subdivisions in evidence. The laboratory strains $P$. aeruginosa NCTC 6750 and ATCC 15692, S. maltophilia NCTC 10247 and B. gladioli ATCC 10248, ATCC 10854 and ATCC 25417 were discriminated from the majority of strains at distances of $0.58,0.53$ and 0.46 Euclids, respectively. Two clinical isolates from Manchester (5RII, 5RIII) did not group with the rest of the B. cepacia strains and, surprisingly, seemed to be most closely associated with S. maltophilia NCTC 10257, although they diverged from this laboratory strain at 0.45 Euclids. This is a higher level than that at which some separately designated species diverge from each other; e.g., B. cepacia and B. vietnamiensis (see below). A third clinical isolate from Manchester (5RI) was more closely associated with the remainder of the UK clinical strains.

Most of the clinical Burkholderia isolates divided into four main clusters at a level of 0.4 Euclids. These clusters are indicated as $1-4$ in Fig. 3. Cluster 4 containined two isolates (J2315 and C1948) previously identified as the CF epidemic lineage ET12 [16]. This cluster appeared to divide into three subgroups ( $a, b$ and $\mathrm{c}$ in Fig. 3) at a level of 0.12 Euclids. Typically, representatives of these subgroups yielded distinctive
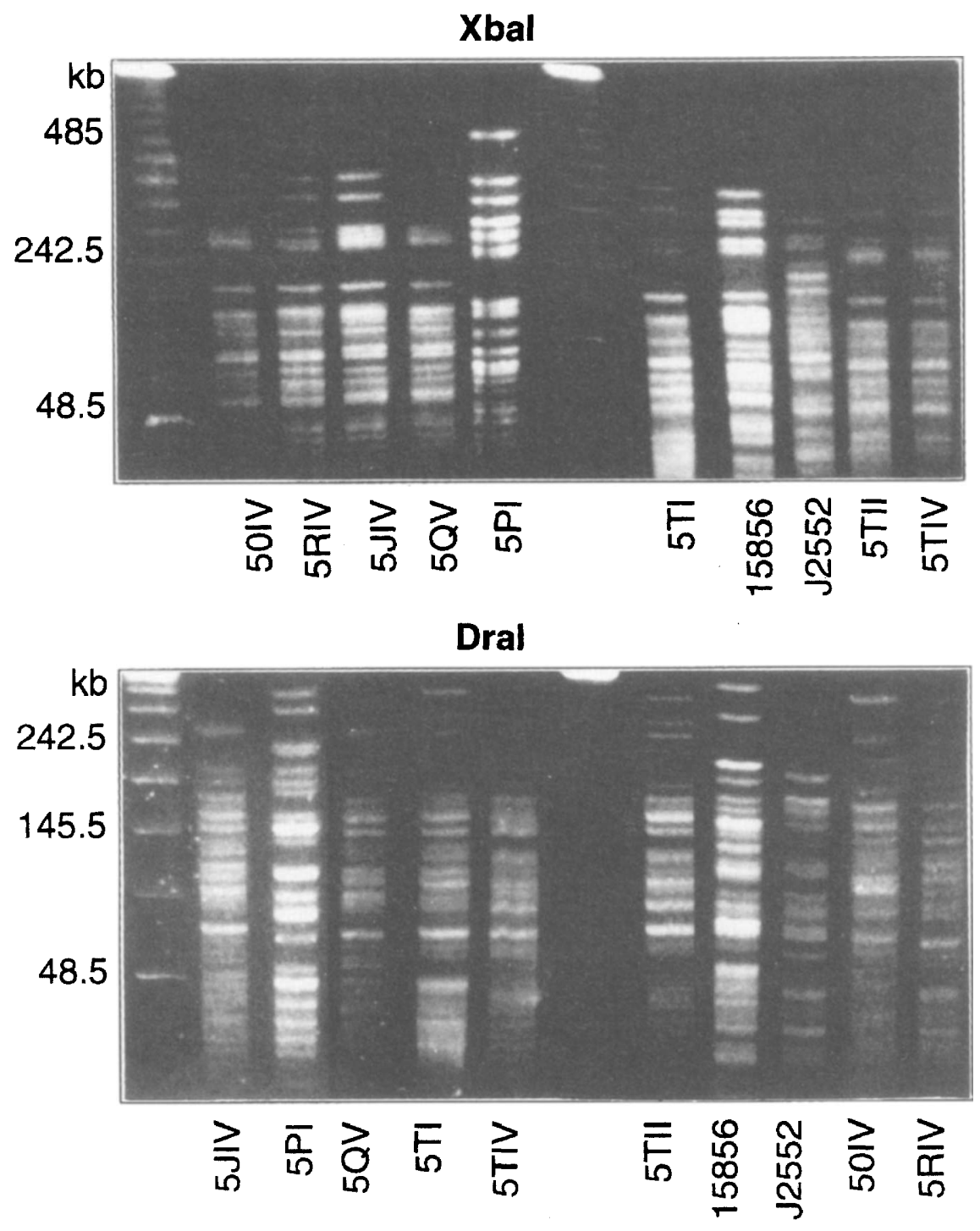

Fig. 2. PFGE showing the characteristic patterns produced by members of cluster 4 (Fig. 3). A lambda ladder (BioRad) provides marker bands in multiples of $48.5 \mathrm{~kb}$. 
Table 2. Relatedness of representative strains, as based on PFGE analysis

\begin{tabular}{|c|c|c|c|c|c|c|c|c|c|c|}
\hline $\begin{array}{l}\text { Strain } \\
\text { no. }\end{array}$ & $\begin{array}{l}\text { NCTC } \\
10257\end{array}$ & $\begin{array}{l}\text { ATCC } \\
10248\end{array}$ & $\begin{array}{l}\text { LMG } \\
6998\end{array}$ & $\begin{array}{l}\text { NCTC } \\
10744\end{array}$ & 4949 & 15856 & $5 \mathrm{PI}$ & $5 \mathrm{SV}$ & 5PIV & $5 \mathrm{JIV}$ \\
\hline NCTC & $0.44^{*}$ & 0.41 & 0.35 & $\mathbf{0 . 3 9}$ & 0.45 & 0.41 & 0.44 & 0.42 & 0.39 & 0.39 \\
\hline 6750 & $(0.37)$ & $(0.52)$ & $(0.44)$ & $(0.41)$ & $(0.43)$ & $(0.49)$ & $(0.45)$ & $(0.48)$ & (0.49) & $(0.48)$ \\
\hline NCTC & & 0.50 & 0.47 & 0.36 & 0.50 & 0.40 & 0.36 & 0.44 & 0.43 & 0.41 \\
\hline 10257 & & $(\mathbf{0 . 5 3})$ & $(0.44)$ & $(0.42)$ & $(0.44)$ & $(\mathbf{0 . 5 2})$ & $(0.46)$ & $(0.47)$ & $(0.48)$ & $(0.48)$ \\
\hline ATCC & & & 0.56 & 0.49 & 0.50 & 0.44 & 0.53 & 0.57 & 0.60 & 0.54 \\
\hline 10248 & & & $(0.63)$ & (0.59) & $(\mathbf{0 . 6 3})$ & $(0.74)$ & $(0.65)$ & (0.69) & $(0.71)$ & $(0.70)$ \\
\hline LMG & & & & 0.69 & 0.52 & 0.63 & 0.47 & 0.69 & 0.57 & 0.68 \\
\hline 6998 & & & & $(0.49)$ & $(0.53)$ & $(0.60)$ & $(0.55)$ & $(0.58)$ & $(0.60)$ & $(0.59)$ \\
\hline NCTC & & & & & 0.72 & 0.63 & 0.60 & 0.62 & 0.58 & 0.70 \\
\hline 10744 & & & & & $(0.49)$ & $(0.55)$ & $(0.51)$ & $(0.54)$ & $(0.55)$ & $(0.55)$ \\
\hline 4949 & & & & & & 0.61 & $\begin{array}{r}0.60 \\
(0.55)\end{array}$ & $\begin{array}{c}0.56 \\
0.58\end{array}$ & $\begin{array}{c}0.54 \\
0.60\end{array}$ & $\begin{array}{r}0.68 \\
(0.59)\end{array}$ \\
\hline 15856 & & & & & & & $\begin{array}{c}0.51 \\
(0.64)\end{array}$ & $\begin{array}{c}0.65 \\
(0.68)\end{array}$ & $\begin{array}{c}0.48 \\
(0.70)\end{array}$ & $\begin{array}{c}0.61 \\
(0.69)\end{array}$ \\
\hline 5PI & & & & & & & & $\begin{array}{c}0.57 \\
(0.61)\end{array}$ & $\begin{array}{c}0.60 \\
(0.62)\end{array}$ & $\begin{array}{c}0.62 \\
(0.60)\end{array}$ \\
\hline $5 \mathrm{SV}$ & & & & & & & & & 0.86 & 0.85 \\
\hline 5PIV & & & & & & & & & $(0.65)$ & $\begin{array}{c}(0.66) \\
0.87 \\
(0.68)\end{array}$ \\
\hline
\end{tabular}

${ }^{*} S_{D}$ between selected pairwise comparisons within the sample (top number in each cell) compared to the lower limit of the $99 \%$ confidence level (in parentheses). If the $S_{D}$ is lower than the confidence limit, then the two strains are significantly dissimilar. Values in bold type represent significant dissimilarities.

banding patterns when digested with $X b a \mathrm{I}$ or Dra I (Fig. 2). These patterns were not found when other isolates were analysed. B. cepacia ATCC 10744, ATCC 17616 and NCTC 10661, and B. vietnamiensis LMG 6998 remained associated with these four clusters of clinical isolates until a distance of 0.41 Euclids, and diverged from each other at a distance of 0.31 Euclids. Thus, representatives of two distinct species - B. cepacia and B. vietnamiensis - were more closely related to each other than to some of the clinical isolates identified as B. cepacia [26]. Fig. 3 also indicates the OMP profile groups determined by SDS-PAGE. All the strains from Denmark belonged to type $A$ and were clustered together in groups 1,2 and 3 of the PFGE dendrogram (Fig. 3). The $15 \mathrm{UK}$ strains with type B OMP profiles were found in PFGE clusters 3 and 4 .

\section{Discussion}

Vandamme et al. [26] recently conducted a comprehensive analysis of presumed strains of $B$. cepacia associated with CF by analysis of whole-cell proteins, fatty acids and by a number of DNA hybridisation methods. This multi-faceted taxonomic approach identified at least five distinct genomic species, referred to as the $B$. cepacia complex. Further differential phenotypic tests are needed to determine the relative importance of members of this complex in $\mathrm{CF}$, particularly members of genomovars I, III and IV [26].

The present study aimed to determine whether OMP profiles were a realistic predictor of genotype as determined by PFGE. Analysis of OMPs by SDSPAGE following denaturation of outer membranes at $100^{\circ} \mathrm{C}$ for $30 \mathrm{~min}$ revealed two different types of profile among isolates from the UK and Denmark. These were distinguished by the presence (type B) or absence (type A) of a cluster of proteins in the region $80-90 \mathrm{kDa}$. All the isolates gave type B profiles when milder conditions were employed for denaturation $\left(80^{\circ} \mathrm{C}\right.$ for $\left.30 \mathrm{~min}\right)$ and group A profiles when more vigorous and extended conditions were employed $\left(100^{\circ} \mathrm{C}\right.$ for $\left.60 \mathrm{~min}\right)$. This temperature-dependent behaviour suggests that the $80-90 \mathrm{kDa}$ proteins are more tightly associated together in the type B strains than in the type A strains and, consequently, were more resistant to denaturation by heat. Lipopolysaccharide (LPS) may play a role in the association of these proteins; previous studies have shown that the 80 $90 \mathrm{kDa}$ protein complex can be dissociated into its lower mol.wt components following electro-elution from the gels [27]. As electro-elution effectively removes LPS from the proteins [28] it is possible that, in the type B strains, the LPS is more tightly associated with these proteins than in the type $A$ strains.

None of the eight CF isolates from Denmark was of type B, whereas a significant proportion (15 of 26) of the CF isolates from the UK, including the epidemic strain $\mathbf{J} 2315$, were of this type. The three $B$. gladioli and one $B$. vietnamiensis strains from culture collections all gave type A OMP profiles. It is interesting that these organisms, which are closely related to $B$. cepacia, share common features in their OMP profiles.

PFGE is a powerful analytical approach for distinguishing epidemiologically related isolates [29] and its application here confirmed the heterogeneity of $B$. 


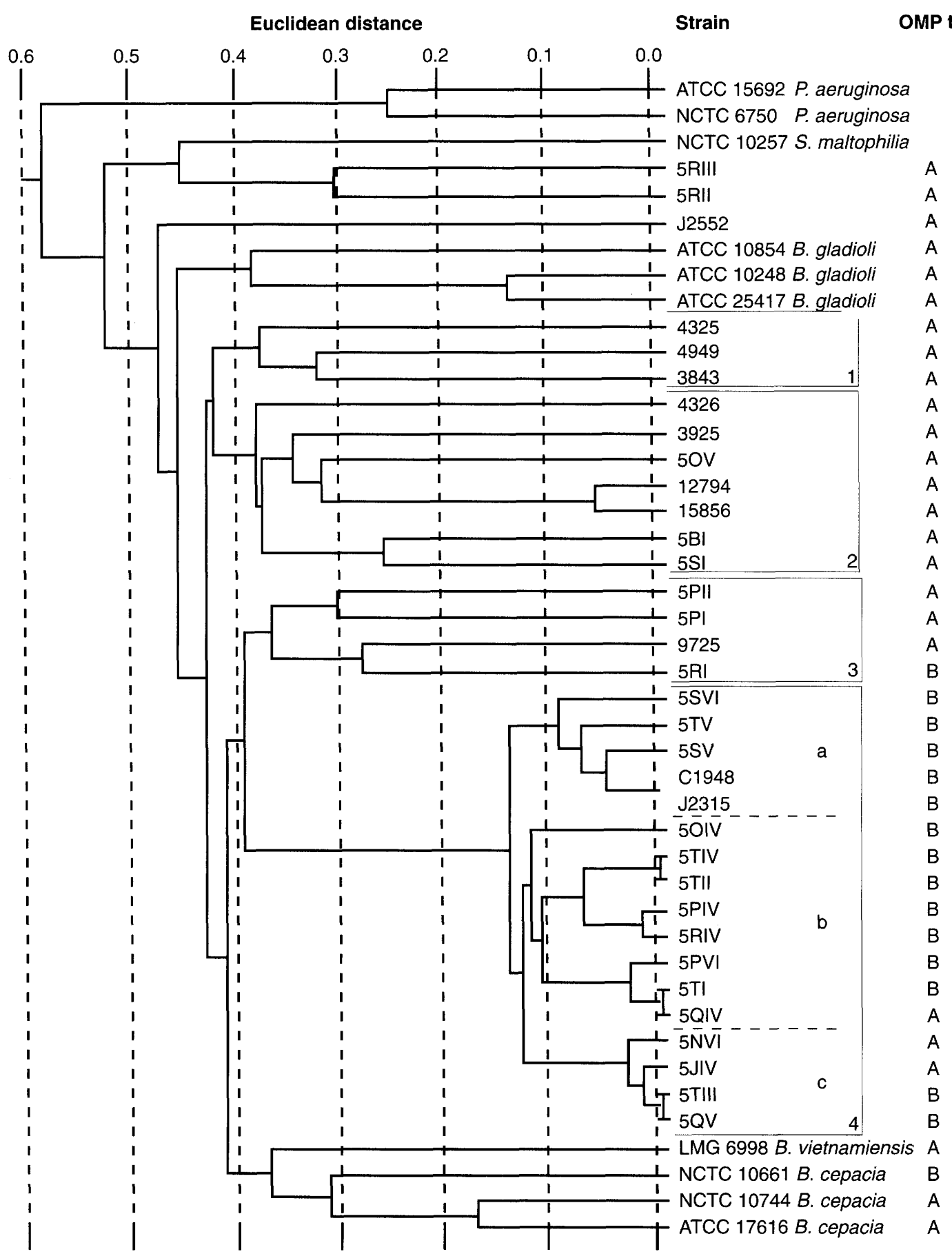

Fig. 3. Dendrogram showing relatedness of the strains, created via cluster analysis of the $S_{D}$ by the UPGMA method.

cepacia isolates from $\mathrm{CF}$ patients described by Vandamme et al. [26]. Four clusters were found, compared with at least five distinct genomic species reported by Vandamme et al. [26], who based their conclusions on a combination of phenotypic and DNA hybridisation methods. The Danish isolates were confined to clusters 1,2 and 3 and shared common type A OMP profiles. All the isolates in clusters 1-4 were less similar to reference isolates of $B$. cepacia than to an isolate of the closely related species, namely $B$. vietnamiensis. B. cepacia and $B$. vietnamiensis were placed at a distance of $c .0 .36$ Euclids from each other (Fig. 3). Recent studies by Gaur and
Wilkinson [30] have identified the same polysaccharide structure in the LPS of the O4 serotype of $B$. cepacia, and a strain of $B$. vietnamiensis, which gives further evidence of their close relationship. Other isolates, considered to be $B$. cepacia in the clinical setting, diverged from these two species at lower levels of similarity (i.e., $>0.36$ Euclids). This result supports a previous review [16] questioning exactly what constitutes ' $B$. cepacia'.

The lower ends of the $99 \%$ confidence limits between certain strains in cluster 4 and reference strains are shown in Table 2, together with the actual $S_{D}$. The 
strains included were selected for their positions within the dendogram (Fig. 3). The lower end of the confidence range is critical here, as this study is concerned primarily with differences between strains, and not with their similarity: if the calculated $S_{D}$ are lower than the confidence value, it is certain that the organisms are significantly different. These confidence values must be viewed with some caution. The confidence equation [24] is heavily dependent upon $I_{K}$, the interval factor, so small variations in $I_{K}$ have a fairly large impact on the confidence value. Moreover, $I_{K}$ is the most subjective parameter in the confidence equation. For these reasons, the results of the confidence equation must be interpreted carefully. The values in bold type in Table 2 indicate the positions where statistical analysis returned a result of significant dissimilarity. The isolates falling within the cluster (PFGE cluster 4) containing representatives of the CF epidemic ET12 lineage were significantly dissimilar to all isolates except $B$. vietnamiensis LMG 6998 and B. cepacia NCTC 10744 and, in the case of isolate $5 \mathrm{JIV}$ only, isolate 5PI.

Previous PFGE studies by Pitt et al. [31] demonstrated four distinct patterns among ET12 isolates, differing by three or fewer bands, one of which was exclusively associated with strains of restricted metabolic capacity. From direct observation, cluster 4 appears to split into three subgroups, designated $\mathrm{a}, \mathrm{b}$ and $\mathrm{c}$ (Fig. 3), with the ET12 isolates falling in cluster $4 \mathrm{a}$. From our previous research, it appears that subgroup clusters differ in metabolic capabilities [32]. Thus cluster 4b contains several strains (5PIV, 5PVI, 5RIV and 5TI) that appear to be auxotrophs and others with limited metabolic capabilities, such as 5QIV [32]. The high prevalence of auxotrophic strains in the CF lung is reasonably explained by Barth and Pitt [33] as being caused by the abundance of nutrients arising from pulmonary damage. More generally, however, a reliance on growth factors and a narrow metabolic capability is not commonly considered a property of $B$. cepacia sensu stricto.

Based on these data, it appears that the species definition of $B$. cepacia has broadened since its original description by Burkholder in 1950 [34] to include several closely related potential species. Further evidence to support this conclusion is provided by Yohalem and Lorbeer $[35,36]$ and the presence of novel species among isolates currently considered as $B$. cepacia - but fitting this species description poorly - has also been suggested by others [16, 26, 37].

The extremes of clinical outcome observed after $B$. cepacia infection in CF may well be rationalised by closer examination of the identity of the infecting organism; however, clinical outcome may not always be predictable even in patients colonised with the same strain. Interactions between host and pathogen are clearly important as most CF individuals, includ- ing those infected with the notorious ET12 lineage and other strains of genomovar III, do not succumb to 'B. cepacia syndrome' $[15,16]$. Nevertheless, more detailed phenotypic and genomic analysis may reveal a subpopulation of Burkholderia with a feature promoting adverse clinical outcomes.

We thank Dr T. L. Pitt and Mrs M. E. Kaufman (PHLS, London) for methodological suggestions regarding PFGE, Mrs D. Townley and Mr R. Tilling for technical assistance.

\section{References}

1. LiPuma JJ, Marks-Austin KA, Holsclaw DS, Winnie GB, Gilligan PH, Stull TL. Inapparent transmission of Pseudomonas (Burkholderia) cepacia among patients with cystic fibrosis. Pediatr Infect Dis J 1994; 13: 716-719.

2. Govan JRW, Deretic V. Microbial pathogenesis in cystic fibrosis: mucoid Pseudomonas aeruginosa and Burkholderia cepacia. Microbiol Rev 1996; 60: 539-574.

3. Lacy DE, Spencer DA, Goldstein A, Weller PH, Darbyshire P. Chronic granulomatous disease presenting in childhood with Pseudomonas cepacia septicaemia. J Infect 1993; 27: 301-304.

4. Verghese A, Al-Samman M, Nabhan D, Naylor AD, Rivera M. Bacterial bronchitis and bronchiectasis in human immunodeficiency virus infection. Arch Intern Med 1994; 154: 2086-2091.

5. Corey M, Farewell V. Determinants of mortality from cystic fibrosis in Canada, 1970-1989. Am J Epidemiol 1996; 143: $1007-1017$.

6. Mortensen JE, Fisher MC, LiPuma JJ. Recovery of Pseudomonas cepacia and other Pseudomonas species from the environment. Infect Control Hosp Epidemiol 1995; 16: 30-32.

7. Butler SL, Doherty CJ, Hughes JE, Nelson JW, Govan JRW. Burkholderia cepacia and cystic fibrosis: do natural environments present a potential hazard? J Clin Microbiol 1995; 33: $1001-1004$.

8. Hobson R, Gould I, Govan JWR. Burkholderia (Pseudomonas) cepacia as a cause of brain abscesses secondary to chronic suppurative otitis media. Eur J Clin Microbiol Infect Dis 1995; 14: $908-911$.

9. Govan JWR, Nelson JW. Microbiology of cystic fibrosis lung infections: themes and issues. J R Soc Med 1993; 86 (Suppl 20): $11-18$.

10. Govan JWR, Nelson JW. Microbiology of lung infection in cystic fibrosis. Br Med Bull 1992; 48: 912-930.

11. Stableforth DE, Smith DL. Pseudomonas cepacia in cystic fibrosis. Thorax 1994; 49: 629-630.

12. Isles A, Maclusky I, Corey $\mathrm{M}$ et al. Pseudomonas cepacia infection in cystic fibrosis: an emerging problem. $J$ Pediatr 1984, 104: 206-210.

13. LiPuma JJ, Dasen SE, Nielson DW, Stern RC, Stull TL. Person-to-person transmission of Pseudomonas cepacia between patients with cystic fibrosis. Lancet 1990; 330: 1094-1096.

14. Ouchi K, Abe M, Karita M, Oguri T, Igari J, Nakazawa T. Analysis of strains of Burkholderia (Pseudomonas) cepacia isolated in a nosocomial outbreak by biochemical and genomic typing. J Clin Microbiol 1995; 33: 2353-2357.

15. Govan JRW, Brown PH, Maddison J et al. Evidence for transmission of Pseudomonas cepacia by social contact in cystic fibrosis. Lancet 1993; 342: 15-19.

16. Govan JWR, Hughes JE, Vandamme P. Burkholderia cepacia: medical, taxonomic and ecological issues. J Med Microbiol 1996; 45: 395-407.

17. Muhdi K, Edenborough FP, Gumery L et al. Outcome for patients colonised with Burkholderia cepacia in Birmingham adult cystic fibrosis clinic and the end of an epidemic. Thorax 1996; 51: 374-377.

18. Sun L, Jiang R-Z, Steinbach $\mathrm{S}$ et al. The emergence of a highly transmissible lineage of $\mathrm{cbl}^{+}$Pseudomonas (Burkholderia) cepacia causing CF centre epidemics in North America and Britain. Nature Med 1995; 1: 661-666.

19. Ryley HC, Ojeniyi B, Hoiby N, Weeks J. Lack of evidence of nosocomial cross-infection by Burkholderia cepacia among 
Danish cystic fibrosis patients. Eur J Clin Microbiol Infect Dis 1996; 15: 755-758.

20. Gotoh N, Nagino K, Wada $K$, Tsujimoto $H$, Nishino $T$. Burkholderia (formerly Pseudomonas) cepacia porin is an oligomer composed of two component proteins. Microbiology 1994; 140: 3285-3291.

21. van Alphen L, van Dam A, Bol P, Spanjaard K, Zanen HC Types and subtypes of 73 strains of Haemophilus influenzae isolated from patients more than 6 years of age with meningitis in the Netherlands. $J$ Infect 1987; 15: 95-101.

22. Parr TR, Moore RA, Moore LV, Hancock REW. Role of porins in intrinsic antibiotic resistance of Pseudomonas cepacia. Antimicrob Agents Chemother 1987; 31: 121-123.

23. Rainey PB, Thompson IP, Palleroni NJ. Genome and fatty acid analysis of Pseudomonas stutzeri. Int J Syst Bacteriol 1994; 44: $54-61$.

24. Grothues D, Tümmler B. New approaches in genome analysis by pulsed-field gel electrophoresis: application to the analysis of Pseudomonas species. Mol Microbiol 1991; 5: 2763-2776.

25. Lugtenberg B, Meijers J, Peters R, van der Hoek P, van Alphen L. Electrophoretic resolution of the 'major outer membrane protein' of Escherichia coli K12 into four bands. FEBS Lett 1975; 58: 254-258.

26. Vandamme P, Holmes B, Vancanneyt $\mathrm{M}$ et al. Occurrence of multiple genomovars of Burkholderia cepacia in cystic fibrosis and proposal of Burkholderia multivorans sp nov. Int $J$ Syst Bacteriol 1997; 47: 1188-1200.

27. Lacy DE, Smith AW, Lambert PA et al. Serum IgG response to an outer membrane porin protein of Burkholderia cepacia in patients with cystic fibrosis. FEMS Immunol Microbiol 1997; 17: $87-94$.

28. Hancock REW, Mouat ECA, Speert DP. Quantitation and identification of antibodies to outer-membrane proteins of Pseudomonas aeruginosa in sera of patients with cystic fibrosis. J Infect Dis 1984; 149: 220-226.
29. Tenover $\mathrm{FC}$, Arbeit RD, Goering $\mathrm{RV}$ et al. Interpreting chromosomal DNA restriction patterns producted by pulsedfield gel electrophoresis: criteria for bacterial strain typing. $J$ Clin Microbiol 1995; 33: 2233-2239.

30. Gaur D, Wilkinson SG. Lipopolysaccharide from Burkholderia vietnamiensis strain LMG 6999 contains two polymers identical to those present in the reference strain for Burkholderia cepacia serogrpup O4. FEMS Microbiol Lett 1997; 157: $183-188$.

31. Pitt TL, Kaufmann ME, Patel PS, Benge LCA, Gaskin S Livermore DM. Type characterisation and antibiotic susceptibility of Burkholderia (Pseudomonas) cepacia isolates from patients with cystic fibrosis in the United Kingdom and the Republic of Ireland. $J$ Med Microbiol 1996; 44: 203-210.

32. Baxter IA, Lambert PA, Simpson IN. Isolation from clinical sources of Burkholderia cepacia possessing characteristics of Burkholderia gladioli. J Antimicrob Chemother 1997; 39: $169-175$.

33. Barth AL, Pitt TL. Auxotrophy of Burkholderia (Pseudomonas) cepacia from cystic fibrosis patients. J Clin Microbiol 1995; 33: $2192-2194$.

34. Burkholder W. Sour skin, a bacterial rot of onion bulbs. Phytopathology 1950; 40: 115-117.

35. Yohalem DS, Lorbeer JW. Intraspecific metabolic diversity among strains of Burkholderia cepacia isolated from decayed onions, soils, and the clinical environment. Antonie van Leeuwenhoek 1994; 65: 111-131.

36. Yohalem DS, Lorbeer JW. Multilocus isoenzyme diversity among strains of Pseudomonas cepacia isolated from decayed onions, soils, and clinical sources. Syst Appl Microbiol 1994; 17: $116-124$.

37. Simpson IN, Finlay J, Winstanley DJ et al. Multi-resistance isolates possessing characteristics of both Burkholderia (Pseudomonas) cepacia and Burkholderia gladioli from patients with cystic fibrosis. J Antimicrob Chemother 1994; 34: 353-361. 